\title{
CAPITAL BUDGETING PADA PROYEK TEKNOLOGI 5G
}

\author{
Tomy Aji Nuraidi \\ Program Studi Magister Manajemen, Universitas Tarumanagara \\ tomyajinuraidi@live.com
}

Masuk : 04-06-2020, revisi : 26-06-2020 diterima untuk diterbitkan : 29-06-2020

\begin{abstract}
The development of digital business and internet technology in the telecommunications industry in Indonesia became a challenge for telecommunications companies, one of which is PT. Telkom Tbk. One study of the strategies that the author carefully regarding the analysis of Capital Budgeting on the 5th Generation (5G) technology project on PT. Telkom Indonesia (Persero) Tbk. and PT Telkomsel Tbk that using the cost benefit method. This study aims to provide a capital budgeting analysis to develop 5G network investment in Indonesia and assess investment feasibility. By using Payback Period calculation, Net Cash Flow and Internal Rate of Return can be identified the potential investment feasibility based on the value of the calculation and then the investment feasibility can be compared. The results show that the calculation of the payback period yields a value of 1.63 years. Whereas the calculation of net present value yields a value of Rp. 189,267 Trillion. For the average rate of return method, the ARR value is $1490.96 \%$. Based on this value, it can be obtained that the $5 \mathrm{G}$ network investment project is feasible to be carried out by PT Telkom Tbk and PT Telkomsel companies.
\end{abstract}

Keywords: Capital Budgeting, Net Present Value, Payback Period, Internal Rate of Return

Abstrak: Perkembangan bisnis digital dan teknologi internet pada industri telekomunikasi di Indonesia menjadi tantangan tersendiri bagi perusahaan telekomunikasi salah satunya PT. Telkom Tbk. Salah satu kajian strategi yang penulis teliti mengenai analisis Capital Budgeting pada proyek teknologi 5th Generation (5G) PT. Telkom Indonesia (Persero) Tbk. dan PT Telkomsel Tbk dengan menggunakan metode cost benefit. Penelitian ini bertujuan memberikan analisis capital budgeting guna mengembangkan investasi jaringan $5 \mathrm{G}$ di negara Indonesia dan menilai kelayakan investasi. Dengan menggunakan perhitungan Payback Period, Net Cash Flow dan Internal Rate of Return dapat diidentifikasi potensi kelayakan investasi berdasarkan nilai perhitungan tersebut dan selanjutnya dapat dibandingakan kelayakan investasi. Hasil menunjukkan untuk perhitungan payback period menghiasilkan nilai 1.63 tahun. Sedangkan perhitungan net present value menghasilkan nilai Rp. 189.267 Triliun. Untuk metode average rate of return nilai ARR adalah 1490,96\%. Dengan berdasarkan nilai tersebut dapat diperoleh bahwa proyek investasi jaringan 5G layak dilakukan perusahaan PT Telkom Tbk dan PT Telkomsel.

Kata kunci: Capital Budgeting, Net Present Value, Payback Period, Internal Rate of Return

\section{PENDAHULUAN}

\section{Latar Belakang}

Teknologi Informasi saat ini kesediaan komunikasi sudah menjadi kebutuhan untuk masyarakat Indonesia. Baik berupa layanan internet, pesan, telepon, video call, sosial media dan lain lain. Di indonesia terdapat Beberapa Jaringan telekomunikasi yang digunakan yaitu 2G, 3G, dan 4G. Salah satu teknologi terbaru pada jaringan telekomunikasi adalah teknologi 5G (Blackman \& Forge, 2019). Dimana teknologi 5G memiliki kelebihan yaitu lebih cepat 100 kali lipat (800Gbps) dari teknologi pendahulunya 4G (Blackman \& Forge, 2019).

Seiring dengan perkembangan teknologi yang semakin cepat, dalam beberapa tahun ke depan layanan cloud pun juga akan mengubah lanskap industri information \& communication 
technology (ICT) (Vidyantina Heppy A., 2018), yang memungkinkan perusahaan untuk menjalankan bisnisnya dengan lebih efektif dan efisien. Perusahaan dapat fokus mengejar keuntungan bisnis dan mengembangkan peluang bisnis baru, tanpa harus membangun dan mengelola data center sendiri.

Dengan terwujudnya National Digital Platform, semua pelaku industri bisa memanfaatkannya untuk men-deliver layanan secara digital maupun melakukan efisiensi produksi dengan teknologi digital. Pengguna internet tidak perlu menjadi konsumen dari apa yang sudah ada di Internet, tetapi dapat menjadi pembuat konten sendiri di World Wide Web (www). Dengan konten yang tepat (apakah itu melibatkan teks, musik, fotografi atau apa pun).

Bisnis digital beberapa tahun belakangan ini telah menjadi sebuah tren usaha yang cukup menggiurkan. Meningkatnya penggunaan internet dan berbagai kemudahan yang ditawarkan oleh smartphone adalah alasan mengapa bisnis ini memiliki peluang baik. Bisnis digital juga menjadi wadah bagi generasi muda untuk menyalurkan kreativitas menjadi sebuah peluang usaha. Banyak juga wirausahawan muda inovatif yang ikut berkontribusi dalam memberikan solusi untuk masalah sosial yang ada melalui bisnis digital.

Ada beberapa peluang bisnis digital di Indonesia yang masih potensial untuk digeluti. Perkembangan bisnis dunia digital yang semakin pesat, telah dipelopori dengan jaringan internet yang semakin cepat berkembang dan pola belanja masyarakat yang berubah dari offline ke online. Beberapa contoh bisnis digital yang sedang berkembang di Indonesia yaitu $E$ Commerce yang melakukan segala aktivitas jual beli yang dilakukan melalui media elektronik. Meskipun sarananya meliputi televisi dan telepon, kini ecommerce lebih sering terjadi melalui internet contohnya di Indonesia Lazada, Tokopedia, Bukalapak dan lainnya.

Bisnis digital membutuhkan konektivitas jaringan internet yang cepat dan handal saat ini di Indonesia mengguna kan teknologi jaringan 4G (4th Generation). Semakin besarnya kebutuhan konektivitas Internet mendorong pula untuk digunakannya teknologi jaringan yang lebih cepat dari jaringan 4G yaitu jaringan 5G (5th Generation). Teknologi 5G memiliki berbagai kelebihan dibanding 4G antara lain kecepatan hingga 50 kali lebih cepat, 10 kali lebih responsif, dan daya konektivitas yang jauh lebih rendah. Berbagai hal ini tersedia berkat kombinasi dari tiga fitur berikut - high throughput, latensi yang sangat rendah, dan konektivitas daya yang juga rendah (Peneliti \& Sdppi, 2018). Peningkatan kecepatan, latensi rendah, dan konektivitas akan membantu operator telekomunikasi dalam menyelenggarakan koneksi Internet super cepat untuk streaming video berkualitas high-definition (HD), cloud gaming, serta konten interaktif berbasis augmented reality dan virtual reality (AR/VR) bagi pelanggannya.

Pada pembangunan teknologi jaringan 5G dibutuhkan jumlah investasi yang besar. Sebagai contoh di Negara Uni Eropa dan Inggris (Oughton \& Frias, 2018) sedang membangun jaringan 5G yang diestimasi menggunakan biaya 42 Triliun rupiah. Dalam rangka mengukur nilai investasi dan mewujudkan teknologi jaringan $5 \mathrm{G}$ yang melayani masyarakat maka akan dibuat analisa capital budgeting pada investasi teknologi jaringan 5G. Keputusan Capital Budgeting pada proyek pengadaan teknologi jaringan 5G akan berpengaruh pada jangka waktu yang lama sehingga perusahaan kehilangan fleksibilitasnya dalam menetukan nilai investasi. Metode capital budgeting yang efektif akan menaikkan ketepatan waktu dan kualitas dari penambahan cashflow bagi perusahaan yang melakukan investasi pada teknologi jaringan $5 \mathrm{G}$ sehingga dapat diketahui nilai keuntungan dari proyek investasi.

\section{Rumusan Masalah}

Berdasarkan uraian pada latar belakang, maka dapat diidentifikasi permasalahannya yaitu:

1. Apakah investasi pada teknologi jaringan 5G akan memberi keuntungan pada perusahaan.

2. Aspek apa saja yang mempengaruhi investasi jaringan $5 \mathrm{G}$ ? 
3. Bagaimana menggunakan metode capital budgeting pada implementasi proyek 5G dan Arus kas pada proyek jaringan 5G?

\section{Tujuan Penelitian}

Berdasarkan rumusan masalah tersebut maka penelitian ini bertujuan Tujuan untuk memberikan kalkulasi yang logis mengenai kebermaknaan investasi teknologi jaringan 5G secara ekonomi dengan menggunakan metode capital budgeting. Hasil analisis ini akan memberikan kepastian yang tinggi pada perusahaan dalam mengambil keputusan investasi.

\section{Ruang Lingkup Penelitian}

Ruang lingkup penelitian Capital Budgeting pada proyek investasi jaringan 5G adalah penelitian dengan melakukan identifikasi Modal investasi pada proyek tersebut. Modal pada investasi proyek teknologi 5G menunjukkan aktiva tetap yang digunakan untuk pembagunan sarana dan fasilitas jaringan (Stelling, Syah, Indrawati, \& Dewanto, 2018). Capital budgeting adalah garis besar rencana pengeluaran aktiva tetap. Penganggaran modal (capital budgeting) adalah proses menyeluruh menganalisa proyek pengadaan Jaringan $5 \mathrm{G}$ dan menentuan mana saja yang dimasukkan ke dalam anggaran modal.

\section{Manfaat Penelitian}

Manfaat dibagi menjadi manfaat bagi pengembangan ilmu dan manfaat operasional. Manfaat bagi pengembangan ilmu, diharapkan penelitian ini dapat memberikan informasi tambahan tentang capital budgeting pada proyek teknologi jaringan 5G yang ada di Indonesia dan memberikan kontribusi dalam pengembangan ilmu di bidang ekonomi dan teknologi (Admaja, 2015), terutama di bidang konsentrasi manajemen keuangan, serta dapat digunakan untuk penelitian selanjutnya yang lebih lanjut dan lebih komprehensif.

Manfaat operasional, diharapkan hasil penelitian ini memberikan wawasan kepada khalayak ramai tentang begitu pentingnya capital budgeting dalam memulai suatu proyek investasi tidak hanya pada penerapan proyek investasi jaringan 5G. Capital Budgeting pada Investasi 5G juga dilakukan agar tidak terjadi kesalahan saat anggara proyek dan investasi sehingga sebagai kontrol dari investasi serta dapat lebih terperinci, teliti karena dana semakin banyak dan dalam jumlah yang sangat besar untuk mencegah terjadinya kesalahan dalam decision making (Al-Ani, 2015).

\section{METODE PENELITIAN \\ Jenis Metode Penelitian}

Pada metode penelitian ini yang penulis lakukan yakni terkait penelitian deskriptif dimana metode yang digunakan untuk mencari unsur-unsur, ciri-ciri, sifat-sifat suatu fenomena. Metode ini dimulai dengan mengumpulkan data, menganalisis data, dan menginterpretasikannya. Pendekatan metode penelitian yang dilakukan dengan menggunakan metode kualitatif dan kuantitatif (campuran).

Peneliti mengumpulkan data yang bersifat kualitatif yakni dengan cara melakukan studi pustaka/pengamatan dan wawancara. Sedangkan data yang bersifat kuantitatif penulis dapatkan dari data internal perusahaan PT. Telkom (Persero) Tbk dan PT. Telkomsel Tbk. serta menganalisisnya untuk menentukan kelayakan investasi jaringan $5 \mathrm{G}$.

\section{Sumber Data}

Data yang diperoleh dalam penelitian ini yakni bersumber dari data sekunder. Data sekunder juga diperoleh dari studi literatur berupa jurnal-jurnal penelitian ataupun artikel yang berkaitan dengan penelitian jaringan $5 \mathrm{G}$.

\section{Metode Analisis}

Penulis melakukan metode dalam analisis pada penelitian ini dengan alur diagram sebagai berikut: 


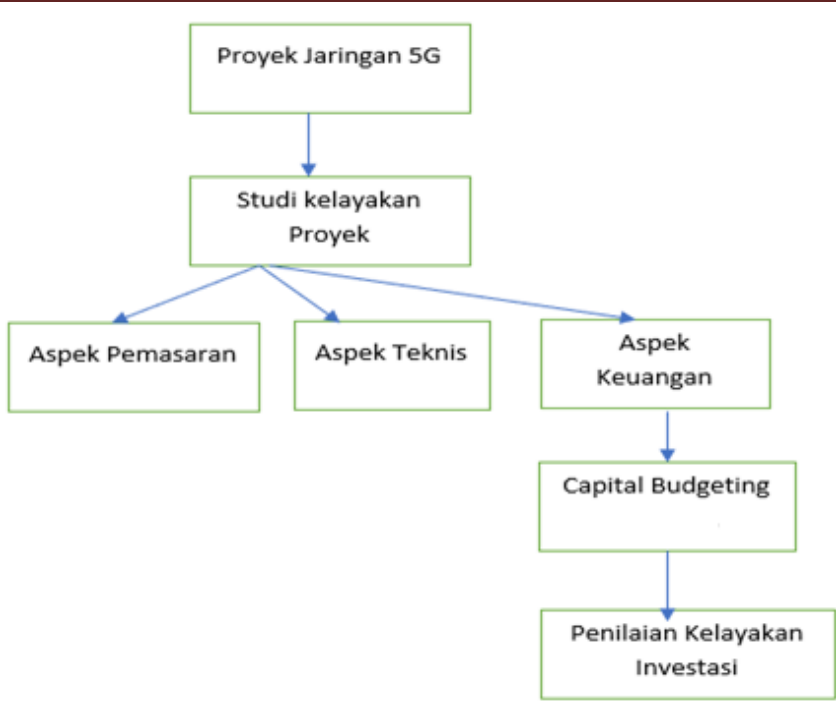

\section{Gambar 1}

Metode Analisis

\section{HASIL DAN PEMBAHASAN}

Metode Payback Period

Dengan menggunakan formulasi payback period (Ardalan, 2012) data yang diperoleh dari investasi jaringan 5G PT. Telkom Tbk untuk sepuluh tahun.

$$
\text { PayBack Period }=\frac{\text { Initial Investment }}{(\text { Cash inflow per period })}
$$

Tabel 1

Data Perhitungan Payback Period Investasi 5G

\begin{tabular}{|c|c|c|}
\hline Tahun & Net Cash Flow (Triliun Rupiah) & Akumulasi Net Cash Flow (Triliun Rupiah) \\
\hline 1 & 24.145 & 24.145 \\
\hline 2 & 28.149 & 52.294 \\
\hline 3 & 34.115 & 86.409 \\
\hline 4 & 42.012 & 128.421 \\
\hline 5 & 51.815 & 127.942 \\
\hline 6 & 63.491 & 157.318 \\
\hline 7 & 76.945 & 192.251 \\
\hline 8 & 92.554 & 232.99 \\
\hline 9 & 109.666 & 279.165 \\
\hline 10 & 128.512 & 330.732 \\
\hline
\end{tabular}

Payback Period $=1,63$

\section{Metode Net Present Value}

Dengan menggunakan formulasi net present value data yang diperoleh dari investasi jaringan 5G PT. Telkom Tbk untuk sepuluh tahun.

$$
N P V=\sum \frac{N C F t}{(1+k)^{t}}-I o
$$

NPV= Net Present Value

$\mathrm{k}=$ suku bunga

$\mathrm{t}=$ periode

Io $=$ investasi awal 
Tabel 2

Data Perhitungan Net Present Value Investasi 5G

\begin{tabular}{|l|l|l|l|}
\hline Tahun & Net Cash Flow & PVIF $(1+15 \%)$ & PV \\
\hline 1 & 24.145 & 0.850 & 20.523 \\
\hline 2 & 28.149 & 0.723 & 20.338 \\
\hline 3 & 34.115 & 0.614 & 20.951 \\
\hline 4 & 42.012 & 0.522 & 21.931 \\
\hline 5 & 51.815 & 0.444 & 22.991 \\
\hline 6 & 63.491 & 0.377 & 23.946 \\
\hline 7 & 76.945 & 0.321 & 24.667 \\
\hline 8 & 92.554 & 0.272 & 25.220 \\
\hline 9 & 109.666 & 0.232 & 25.401 \\
\hline 10 & 128.512 & 0.197 & 25.301 \\
\hline
\end{tabular}

Nilai Sekarang $\mathrm{NCF}=231.267$

Investasi Awal $=42$

Net Present Value $=189.267$

Karena nilai net present value lebih dari 0 makan project investasi jaringan 5G layak untuk dilakukan.

\section{Metode Internal Rate of Return}

Dengan menggunakan formulasi internal rate of return (Osborne, 2016) data yang diperoleh dari investasi jaringan 5G PT. Telkom Tbk untuk sepuluh tahun. Dengan Rumus:

$$
I_{o}=\sum_{t=1}^{n} \frac{F C F_{t}}{(1+I R R)^{t}}
$$

Tabel 3

Data Perhitungan Internal Rate of Return Investasi 5G

\begin{tabular}{|l|l|}
\hline Tahun & Net Cash Flow \\
\hline 2022 & 24.145 \\
\hline 2023 & 28.149 \\
\hline 2024 & 34.115 \\
\hline 2025 & 42.012 \\
\hline 2026 & 51.815 \\
\hline 2027 & 63.491 \\
\hline 2028 & 76.945 \\
\hline 2029 & 92.554 \\
\hline 2030 & 109.666 \\
\hline 2031 & 128.512 \\
\hline
\end{tabular}

Berdasarkan Perhitungan interpolasi IRR didapatkan nilai 32,46\% lebih besar dari suku bunga investasi yang digunakan saat ini yaitu $15 \%$.

\section{KESIMPULAN DAN SARAN}

Hasil penelitian ini untuk mengetahui apakah proyek investasi 5G akan layak untuk dijalankan dan memberikan keuntungan bagi perusahaan dengan melakukan penilaian investasi atasi periode pengembalian (payback period), Nilai Bersih Sekarang (Net Present Value), dan internal tingkat pengembalian (internal rate of return).

\section{Tabel 4}

\section{Rangkuman Perhitungan Capita Budgeting Investasi 5G}

\begin{tabular}{|l|l|l|l|}
\hline No & Metode & Nilai & Kelayakan \\
\hline 1 & Payback Period & 1,63 Tahun Modal Kembali & Layak \\
\hline 2 & Net Present Value & 189.267 Triliun Rupiah & Layak \\
\hline 3 & Internal Rate of Return & $32.46 \%$ & Layak \\
\hline
\end{tabular}

Berdasarkan tabel 4, perhitungan penilaian investasi, rencana investasi jaringan 5G layak untuk dijalankan. Karena memiliki periode pengembalian yang kurang dari umur investasi (payback period =1,63 tahun berbanding 10 tahun umur investasi), IRR ini sebesar $32,46 \%$ dan Nilai bersih Sekarang (net present value) NPV $=$ Rp 189,267 Triliun $>0$. 


\section{UCAPAN TERIMA KASIH}

Penulis mengucap syukur kepada Tuhan Yang Maha Esa bahwa penulisan capital budgeting pada proyek jaringan 5G pada PT. Telkom Tbk dan PT. Telkomsel Tbk dapat terselesaikan. Selain itu penulis mengucapkan terima kasih kepada Jajaran Dosen dan Dosen Pembimbing di Universitas Tarumanagara Program Studi Magister Manajemen atas ilmu dan bimbingan yang telah diberikan kepada penulis. Tak lupa dukungan keluarga yang telah diberikan kepada penulis sehingga penulisan ini dapat terselesaikan.

\section{REFERENSI}

Admaja, A. F. S. (2015). Kajian awal 5G Indonesia (5G Indonesia early preview). Buletin Pos dan Telekomunikasi, 13(2), 97. https://doi.org/10.17933/bpostel.2015.130201

Al-Ani, M. K. (2015). A strategic framework to use payback period in evaluating the capital budgeting in energy and oil and gas sectors in Oman. International Journal of Economics and Financial Issues, 5(2), 469-475.

Ardalan, K. (2012). Payback period and NPV: Their different cash flows. Journal of Economics and Finance Education, 11(2), 10-16.

Blackman, C., \& Forge, S. (2019). 5G Deployment: State of play in Europe, USA and Asia. Policy Department for Economic, Scientific and Quality of Life Policies, (April). Retrieved from https://www.europarl.europa.eu/RegData/etudes/IDAN/2019/631060/IPOL_IDA(2019) 631060_EN.pdf\%0Ahttp://www.europarl.europa.eu/RegData/etudes/IDAN/2019/63106 0/IPOL_IDA(2019)631060_EN.pdf

Osborne, M. (2016). A note on the IRR of a project with many potential outcomes. SSRN Electronic Journal, (September 2016), 1-8. https://doi.org/10.2139/ssrn.2830480

Oughton, E. J., \& Frias, Z. (2018). The cost, coverage and rollout implications of 5G infrastructure in Britain. Telecommunications Policy, 42(8), 636-652. https://doi.org/10.1016/j.telpol.2017.07.009

Peneliti, T., \& Sdppi, P. (2018). Studi Lanjutan 5G Indonesia 2018 Spektrum Outlook dan Use Case untuk Layanan $5 G$ Indonesia.

Stelling, S., Syah, T. Y. R., Indrawati, R., \& Dewanto, D. (2018). Role of payback period, ROI, and NPV for investment in clinical health business. International Advanced Research Journal in Science, Engineering and Technology ISO, 3297, 78-82. https://doi.org/10.17148.IARJSET.2018.5714

Vidyantina, H. A. D. (2018). Analisa Industri Telekomunikasi Indonesia untuk Mendukung Efisiensi. SDDPPI Kemenkominfo. 